\title{
Anaesthesia suitable for prolonged bronchoscopic examination
}

\author{
E. C. ATTWOOD, W. BROOKS, and W. J. H. LECKIE \\ The County Hospital, Hereford
}

\begin{abstract}
A technique of combined general and topical anaesthesia is described involving spontaneous ventilation. Patients aged 46 to 76 were examined in this way for periods varying between 5 and 25 minutes. Carbon dioxide elimination was satisfactory in all but 2 of 18 patients, and these 2 are discussed in detail. Capillary oxygen tension was maintained at a level of over $75 \mathrm{~mm}$. $\mathrm{Hg}$ throughout all 11 examinations where oxygen was introduced at the proximal end of the bronchoscope, but dangerous hypoxaemia occurred in 2 patients in whom oxygen was not administered in this way.
\end{abstract}

The most commonly employed techniques of general anaesthesia for adult bronchoscopy involve either the production of apnoea with intermittent ventilation or carinal oxygen insufflation with prolonged apnoea or intermitten $t$ abdominal compression. Topical anaesthesia alone for bronchoscopic examination is in general becoming less popular although it is still advocated by some because using this technique arterial $p \mathrm{H}, \mathrm{PaCO}_{2}$, and $\mathrm{PaO}_{2}$ levels have remained unchanged (Kwon, Chiu, Golding, Garzon, and Karlson, 1968). However there is no doubt that for the majority of patients, bronchoscopy with topical anaesthesia is an unpleasant experience and as such there can be an emotional bias against its use which may not be in the patient's best interests. On the other hand, it does allow prolonged examination which can be of the utmost importance during instruction when the apprentice bronchoscopist may take as long as 20 minutes to identify the normally accessible bronchial orifices.

There is clearly a need for a technique of general anaesthesia which permits a relatively lengthy examination of the patient. Jenkins and Sammons (1968) compared the method of intermittent ventilation via the bronchoscope described by Churchill-Davidson (1953) and apnoeic oxygenation as described by Cheatle and Chambers (1955) and further investigated by Boulton, Cole, and Langton Hewer (1965) and Zeitlin, Short, and Fielding (1965). They found an average rise of $\mathrm{PaCO}_{2}$ in the former of $2.7 \mathrm{~mm} . \mathrm{Hg} / \mathrm{min}$. with a maximum of $4.3 \mathrm{~mm} . \mathrm{Hg} / \mathrm{min}$., and in the latter $3.4 \mathrm{~mm}$. $\mathrm{Hg} / \mathrm{min}$., with a maximum of $6.3 \mathrm{~mm}$. $\mathrm{Hg} / \mathrm{min}$. Fluctuations in oxygen tension were not measured in this investigation but were demonstrated by Wylie and Churchill-Davidson (1966), where interruptions in bronchoscopy proved nzcessary to maintain adequate levels of oxygen tension.

A technique of combined general and topical anaesthesia allowing spontaneous ventilation had proved very satisfactory without significant complication in over 200 cases in clinical practice, and it was decided to meter $\mathrm{PaCO}_{2}$ and $\mathrm{PaO}_{2}$ during a series of routine bronchoscopic examinations, so as to obtain an accurate biochemical evaluation of this method of anaesthesia.

\section{PATIENTS AND METHODS}

Nineteen patients were included in the study and the relative clinical data are listed in the Table. All were patients undergoing diagnostic bronchoscopy and all had satisfactory peripheral circulation.

Capillary samples were taken by fingerprick (as I the ear lobe was not easily accessible during bronchoscopy) after the hand and forearm had been warmed by water bottle and blanket for at least 30 minutes. $\mathcal{S}$ The samples were collected in heparinized capillary $N$ tubes, immediately sealed with plasticine to avoid $\mathrm{N}$ contact with atmospheric oxygen, and stored in iced $\omega$ water at $4^{\circ} \mathrm{C}$. until analysed. Previous comparison of arterial and capillary $\mathrm{PaCO}_{2}$ collected in this way simultaneously from 28 patients showed a mean of $\bar{D}$ $69.4 \mathrm{~mm}$. $\mathrm{Hg}$ (range 27 to $102 \mathrm{~mm}$. $\mathrm{Hg}$ ) for the arterial $\stackrel{\mathscr{C}}{?}$ and a mean of $68.1 \mathrm{~mm} . \mathrm{Hg}$ (range 27 to $102 \mathrm{~mm} . \mathrm{Hg}$ ) for the capillary samples. The samples were collected $\bar{O}$ initially after at least 30 minutes' complete bed rest $\overrightarrow{\mathbb{D}}$ and then continuously from about the time of the introduction of the bronchoscope until the comple- $\varrho$ tion of the examination, care being taken to avoid $\underset{\gamma}{ }$ 
T A B L E

CLINICAL DATA

\begin{tabular}{|c|c|c|c|c|c|c|c|}
\hline $\begin{array}{c}\text { Case } \\
1 \\
2 \\
3 \\
4\end{array}$ & \multicolumn{2}{|c|}{ Sex/Age } & $\begin{array}{c}\text { Diagnosis } \\
\text { uppurative pneumonia }\end{array}$ & \multicolumn{2}{|c|}{$\underset{(\mathrm{ml} .)}{\mathrm{FEV}_{1} \text { FVC }}$} & \multicolumn{2}{|c|}{$\begin{array}{c}\text { Resting } \\
\mathrm{PaCO}_{2} \mathbf{P a O}_{2} \\
\left(\mathrm{~mm}^{2} \mathrm{Hg}\right)\end{array}$} \\
\hline $\begin{array}{r}1 \\
2 \\
3 \\
4 \\
5 \\
6 \\
7 \\
8 \\
9 \\
10 \\
11 \\
12 \\
13 \\
14 \\
15 \\
16 \\
17 \\
18 \\
19\end{array}$ & \begin{tabular}{|l}
$\mathbf{M}$ \\
$\mathbf{M}$ \\
$\mathbf{M}$ \\
$\mathbf{M}$ \\
$\mathbf{F}$ \\
$\mathbf{M}$ \\
$\mathbf{M}$ \\
$\mathbf{M}$ \\
$\mathbf{M}$ \\
$\mathbf{M}$ \\
$\mathbf{M}$ \\
$\mathbf{M}$ \\
$\mathbf{M}$ \\
$\mathbf{M}$ \\
$\mathbf{F}$ \\
$\mathbf{M}$ \\
$\mathbf{M}$ \\
$\mathbf{M}$ \\
$\mathbf{M}$
\end{tabular} & $\begin{array}{l}50 \\
57 \\
39 \\
66 \\
51 \\
62 \\
54 \\
50 \\
52 \\
56 \\
50 \\
60 \\
72 \\
69 \\
52 \\
48 \\
55 \\
70 \\
76\end{array}$ & $\begin{array}{l}\text { Suppurative pneumonia } \\
\text { Bronchial carcinoma } \\
\text { Sarcoidosis } \\
\text { Empyema } \\
\text { Bronchial carcinoma } \\
\text { Bronchial carcinoma } \\
\text { Bronchial carinoma } \\
\text { Bronchial carcinoma } \\
\text { Bronchial carcinoma } \\
\text { Bronchial carcinoma } \\
\text { Bronchial carcinoma } \\
\text { Bronchial carcinoma } \\
\text { Bronchial carcinoma } \\
\text { Oesophageal carcinoma } \\
\text { Bronchial carcinoma } \\
\text { Suppurative pneumonia } \\
\text { Bronchial carcinoma } \\
\text { Bronchial carcinoma } \\
\text { Bronchial carcinoma }\end{array}$ & $\begin{array}{r}2,900 \\
1,150 \\
1,100 \\
1,800 \\
1,250 \\
1,500 \\
1,800 \\
875 \\
1,500 \\
1,800 \\
2,525 \\
900 \\
800 \\
1,600 \\
1,500 \\
2,700 \\
1,900 \\
1,700 \\
1,250\end{array}$ & $\begin{array}{l}4,100 \\
1,350 \\
1,900 \\
2,475 \\
1,500 \\
2,800 \\
3,300 \\
1,125 \\
2,250 \\
3,000 \\
3,150 \\
1,350 \\
1,900 \\
2,300 \\
2,000 \\
4,150 \\
2,500 \\
2,900 \\
2,275\end{array}$ & $\begin{array}{l}39 \\
47 \\
31 \cdot 5 \\
39 \\
36 \\
37 \\
32 \\
32 \cdot 5 \\
35 \\
36 \\
32 \\
45 \cdot 5 \\
39 \\
35 \\
39 \\
28 \cdot 5 \\
36 \cdot 5 \\
32 \cdot 5\end{array}$ & $\begin{array}{r}68 \\
60 \\
51 \\
557 \\
71 \\
63 \\
51 \\
68 \\
556 \\
69 \\
59 \\
552 \\
68 \\
73 \\
70 \\
5559 \\
563 \\
560\end{array}$ \\
\hline
\end{tabular}

The first eight patients were given air, but there was a modified technique with oxygen for patients 9 to 19 .

any venous tourniquet effect. The time of taking each specimen was accurately related to the time of introduction of the bronchoscope. A mean of seven samples were taken from each patient during bronchoscopy (range 5 to 10 ).

The blood samples were analysed within 30 minutes of collection. $\mathrm{PaCO}_{2}$ and $\mathrm{pH}$ were measured with the Astrup microglass electrode and equilibrating apparatus (Astrup, Jørgensen, Andersen, and Engel, 1960). $\mathrm{PaO}_{2}$ was measured with a Clark-type oxygen electrode (type E5046), supplied and used in conjunction with the Astrup apparatus. Using the micro-thermostatted cell, volumes as small as $70 \mu \mathrm{l}$. blood can be used for $\mathrm{PaO}_{2}$ determination.

\section{ANAESTHETIC TECHNIQUE}

Atropine, $0.6 \mathrm{mg}$, was administered by intramuscular injection to each patient approximately half an hour prior to anaesthesia.

Anaesthesia was induced with sodium thiopentone, 200-400 mg., immediately followed by gallamine, $40-80 \mathrm{mg}$. The amount of both these drugs used depended upon the patient's general fitness and physique. The dose of gallamine was $60 \mathrm{mg}$. in all but three cases. Provided that breathing continued, the larynx was visualized and sprayed during each inspiration with 4\% lignocaine solution from a DeVilbiss spray. Excess local anaesthetic was sucked from the hypopharynx, so that although the total volume of lignocaine used was noted, the fraction of this volume ultimately absorbed was unknown. It was, however, unlikely ever to exceed the maximum dose level of $6 \mathrm{mg}$./kg. recommended by Bromage and Robson (1961).

In those patients who became apnoeic after the induction, the lungs were gently ventilated with oxygen (5 1./min.) through a Magill circuit until respiration returned, when the respiratory tract was sprayed with local anaesthetic.

During positioning on the operating table and preparation for bronchoscopy all patients breathed halothane $2-4 \%$ in oxygen at a flow rate of $51 . / \mathrm{min}$. During bronchoscopy the first eight patients breathed air, but in the subsequent 11 cases oxygen was administered through the side tube of the Negus bronchoscope at a flow rate of $51 . / \mathrm{min}$.. halothane $1-4 \%$ being added. This maintained tranquillity without further injections of thiopentone, but in the first eight cases incremental doses of thiopentone $(50 \mathrm{mg}$.) were often required to deepen anaesthesia.

The effect of gallamine was reversed in all patients at the end of the examination by intravenous injection of neostigmine, $2.5 \mathrm{mg}$., preceded by atropine, $1.2 \mathrm{mg}$., after oxygenation. The recovery time was measured from the time of completion of bronchoscopy until the time of response to verbal commands.

\section{RESULTS}

All subjects were satisfactorily anaesthetized and in all except case 3 prolonged examination was possible, the time of bronchoscopy ranging from 5 to 25 minutes (mean 11.8 minutes). The resting $\mathrm{PaO}_{2}$ values ranged from 51 to $73 \mathrm{~mm}$. $\mathrm{Hg}$ (mean $62.2 \mathrm{~mm}$. $\mathrm{Hg}$ ). In two patients the $\mathrm{PaO}_{2}$ fell briefly to levels of less than $40 \mathrm{~mm}$. $\mathbf{H g}$, and after the results of case 8 were known it was agreed that oxygen must be administered during the bronchoscopy and this was achieved as indicated above. Only one value under $75 \mathrm{~mm}$. Hg during bronchoscopy was subsequently obtained and this occurred withir 30 seconds of the introduction of the bronchoscope, the value being $90 \mathrm{~mm}$. $\mathrm{Hg}$ one and a half minutes later. $\mathrm{PaO}_{2}$ levels for individua! patients are shown in Figures 1 and 2 .

Only one patient (case 3) developed evidence of serious hypoventilation, the $\mathrm{PaCO}_{2}$ rising to 135 $\mathrm{mm}$. $\mathrm{Hg}$ at a time when his $\mathrm{PaO}_{2}$ was $40 \mathrm{~mm}$. $\mathbf{H g}$. There was no statistically significant difference between the behaviour of the $\mathrm{PaCO}_{2}$ level in those patients who were receiving oxygen during bronchoscopy and those who were not. There was a consistent tendency of the $\mathrm{PaCO}_{2}$ to drop in both groups from a value which was always slightly elevated immediately before the introduction of the bronchoscope (range 46 to $90 \mathrm{~mm}$. $\mathrm{Hg}$, mean $62.3 \mathrm{~mm}$. $\mathrm{Hg}$ ). $\mathrm{PaCO}_{2}$ levels for individual patients are shown in Figures 3 and 4.

The mean recovery time was 7 minutes (range $1 \frac{1}{2}-19$ min.).

\section{DISCUSSION}

Whitehead (1967) has concluded that, with certain precautions, the results using capillary blood for 

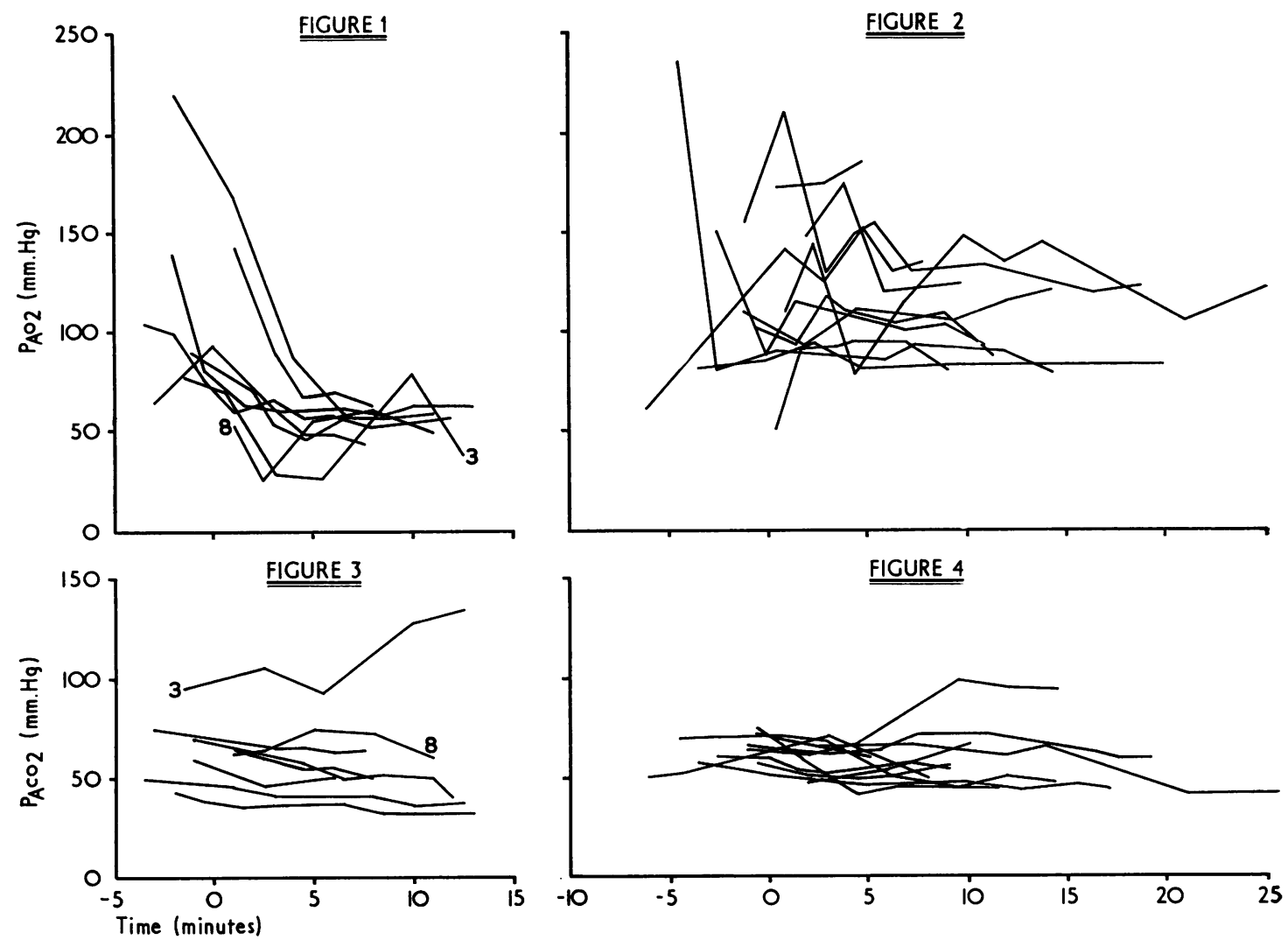

FIG. 1. Capillary oxygen tension levels during bronchoscopy in cases 1 to 8 . 0 min. represents the time of introduction of the bronchoscope. The curves for cases 3 and 8 are labelled 3 and 8 respectively. Oxygen was not administered during bronchoscopy.

FIG. 2. Capillary oxygen tension levels during bronchoscopy in cases 9 to 19.0 min. represents the time of introduction of the bronchoscope. Oxygen was administered during bronchoscopy.

FIG. 3. Capillary carbon dioxide tension levels during bronchoscopy in cases 1 to 8.0 min. represents the time of introduction of the bronchoscope. The curves for cases 3 and 8 are designated 3 and 8 respectively. Oxygen was not administered during bronchoscopy.

FIG. 4. Capillary carbon dioxide tension levels during bronchoscopy in cases 9 to 19.0 min. represents the time of introduction of the bronchoscope. Oxygen was administered during bronchoscopy.

the measurement of the $\mathrm{PaCO}_{2}$ are comparable with those using arterial blood. Using the same precautions, we have also confirmed that in the $\mathrm{PaO}_{2}$ determinations there is a close correlation between capillary and arterial samples. Since during bronchoscopy samples were taken almost continuously, we thought that paired samples would not be required, and in fact the majority of the estimations demonstrated a consistent change.

For the bronchoscopist the method provides all that can be desired. The bronchoscope is unobstructed for use of either suction, telescopes or forceps and an interrupted examination can take as long as is required.

In the first series of eight patients, the bronchoscopy was clearly unsafe in two, the $\mathrm{PaO}_{2}$ falling to $22 \mathrm{~mm} . \mathrm{Hg}$ in one (case 3) and to $26 \mathrm{~mm} . \mathrm{Hg}$ in the other (case 8). The first patient suffered from airways obstruction, patchy pulmenary consolidation, and was later shown to have endobronchial sarcoidosis. He was 37 years old and had an FEV of $1,100 \mathrm{ml}$. and FVC of $1,900 \mathrm{ml}$. The resting $\mathrm{PaO}_{2}$ and $\mathrm{PaCO}_{2}$ were 57 and $47 \mathrm{~mm}$. $\mathrm{Hg}$ respectively. The second patient was a man 
of 50 with central carcinoma and cerebral metastasis. $\mathrm{His} \mathrm{FEV}_{1}$ was $1,400 \mathrm{ml}$. and FVC 1,900 ml., the resting $\mathrm{PaO}_{2}$ was $68 \mathrm{~mm}$. $\mathrm{Hg}$ and the $\mathrm{Paco}_{2}$ was $33 \mathrm{~mm}$. Hg. It did not seem possible, therefore, from resting blood gas levels or ventilatory function to predict which patients would seriously hypoventilate. The introduction of oxygen into the side tube of the bronchoscope in cases 9 to 19 prevented the oxygen tension falling below $50 \mathrm{~mm}$. $\mathrm{Hg}$, and indeed it was only below $80 \mathrm{~mm}$. $\mathrm{Hg}$ in two patients. Although the $\mathrm{PaCO}_{2}$ at the outset was raised above normal in all patients, in only one did it rise above $70 \mathrm{~mm}$. $\mathrm{Hg}$. This was a man of 72 (case 13) who had very extensive tumour and bronchitis with an $\mathrm{FEV}_{1}$ of $800 \mathrm{ml}$. and an FVC of $1,850 \mathrm{ml}$. His resting $\mathrm{PaCO}_{2}$ was at the upper level of the normal range at $45.5 \mathrm{~mm}$. Hg.

Morgan, Lumley, McCormick, and Stradling (1969) point out that several workers have shown that a normal $\mathrm{O}_{2}$ saturation and a normal or reduced $\mathrm{PaCO}_{2}$ can be obtained using a ventilation bronchoscope. However, there is some inconvenience for the bronchoscopist. Indirect ventilation by cuirass is a rather cumbersome procedure and causes pre-anaesthetic disturbance to the patients. It often fits badly and its limitations have been described by Safar (1958). The levels of $\mathrm{PaCO}_{2}$ found in the second group of patients were within the mean cardiac arrhythmia threshold found by Black, Linde, Dripps, and Price (1959), and the mean of the highest values for each patient was beneath the mean arrhythmia threshold level found by Price, Lurie, Black, Sechzer, Linde, and Price (1960) when halothane was used.

Riding and Robinson (1961) have described an increased incidence of cardiac arrhythmia unless alkalosis is induced by hyperventilation before neostigmine reversal. This would be a wise precaution in view of the mild hypercapnia frequently found in these patients.

The level of $\mathrm{PaO}_{2}$ was very satisfactory in the second group of patients, only falling momentarily below $60 \mathrm{~mm}$. $\mathrm{Hg}$ in one patient. However, $\mathrm{PaO}_{2}$ levels were generally too low in group $I$ and it is obviously essential, if this method of anaesthesia is to be employed, for oxygen to be administered during bronchoscopy as described. Nevertheless, we have carried out over 500 bronchoscopies in the past four and a half years without mortality, at least two-thirds of the patients being anaesthetized without this refinement.

The results of blood gas analysis in the second group of patients compare well with those described in any other non-ventilated series. Jenkins and Sammons (1968) demonstrated a mean rise in $\mathrm{PaCO}_{2}$ in their better group (the ventilation series) of $2.7 \mathrm{~mm}$. $\mathrm{Hg} / \mathrm{min}$, with a range of 1.6 to $4.3 \mathrm{~mm}$. $\mathrm{Hg} / \mathrm{min}$. This cannot safely allow uninterrupted bronchoscopy for more than 12 minutes since the $\mathbf{P a O}_{2}$ levels were not estimated. Morales, Epstein, Cinco, Adkins, and Coakley (1969) noticed a mean rise of $\mathrm{PaCO}_{2}$ of between 2.5 and $4 \mathrm{~mm}$. $\mathrm{Hg} / \mathrm{min}$. in patients who underwent ventilation by means of an open bronchoscope, ventilating bronchoscope, and insufflation as described in their paper. Only when using Sanders intermittent Venturi injector technique were they able to keep the $\mathrm{PaCO}_{2}$ to a rise of no more than $1 \mathrm{~mm}$. $\mathrm{Hg} / \mathrm{min}$., and they did not mention the range of values. In our investigation, mean $\mathrm{PaCO}_{2}$ fell from the beginning of bronchoscopy at a rate of $0.34 \mathrm{~mm}$. $\mathrm{Hg} / \mathrm{min}$., although there was a net rise from resting values prior to premedication and the induction of general anaesthesia of $1.5 \mathrm{~mm}$. $\mathrm{Hg} / \mathrm{min}$.

\section{REFERENCES}

Astrup, P., Jørgensen, K., Andersen, O. S., and Engel, K. (1960). The acid-base metabolism: a new approach. Lancet, 1, 1035.

Black, G. W., Linde, H. W., Dripps, R. D., and Price, H. L. (1959). Circulatory changes accompanying respiratory acidosis during halothane (Fluothane) anaesthesia in man. Brit. J. Anaesth., 31, 238.

Boulton, T. B., Cole, P. V., and Langton Hewer, C. (1965). A reassessment of anaesthesia by endotracheal insufflation. Anaes. thesia, 20, 442.

Bromage, P. R., and Robson, J. G. (1961). Concentrations of lignocaine in the blood after intravenous, intramuscular, epidural and endotracheal administration. Anaesthesia, 16, 461 .

Cheatle, C. A., and Chambers, K. B. (1955). Anaesthesia for bronchoscopy. Anaesthesia, 10, 171.

Churchill-Davidson, H. C. (1953). Anaesthesia for bronchoscopy. Anaesthesia, 8, 128.

Jenkins, A. V., and Sammons, H. G. (1968). Carbon dioxide elimination during bronchoscopy: a comparison of two alternative general anaesthetic techniques. Brit. J. Anaesth., 40, 533.

Kwon, K., Chiu, C. J., Golding, M. R., Garzon, A. A., and Karlson, K. E. (1968). Effect of bronchoscopy with premedication and topical anesthesia on arterial blood gases. Arch. Surg., 97, 648.

Morales, G. A., Epstein, B. S., Cinco, B., Adkins, P. C., and Coakley, C. S. (1969). Ventilation during general anesthesia for bronchoscopy. J. thorac. cardiovasc. Surg., 57, 873.

Morgan, M., Lumley, J., McCormick, P. W., and Stradling, P. (1969). Anesthesia for bronchoscopic photography. Anaesthesia, 24, 343.

Price, H. L., Lurie, A. A., Black, G. W., Sechzer, P. H., Linde, H. W., and Price, M. L. (1960). Modification by general anesthetics (cyclopropane and halothane) of circulatory and sympathoadrenal responses to respiratory acidosis. Ann. Surg., 142, 1071.

Riding, J. E., and Robinson, J. S. (1961). The safety of neostigmine. Anaesthesia, 16, 346.

Safar, P. (1958). Ventilating bronchoscope. Anesthesiology, 19, 406.

Whitehead, T. P. (1967). Blood hydrogen ion: terminology, physiology, and clinical applications. Advanc. clin. Chem., 9, 195.

Wylie, W. D., and Churchill-Davidson, H. C. (1966). A Practice of Anaesthesia. 2nd ed., p. 324. Lloyd-Luke, London.

Zeitlin, G. L., Short, D. H., and Fielding, M. E. (1965). Carbon dioxide elimination during insufflation anaesthesia. Brit. $J$. Anaesth., 37, 117. 